TITLE:

\title{
Three Forms of Nauplius Y Type VIII Larvae (Crustacea : Facetotecta) from the North Pacific
}

\author{
$\operatorname{AUTHOR}(\mathrm{S}):$ \\ Ito, Tatsunori
}

\section{CITATION:}

Ito, Tatsunori. Three Forms of Nauplius Y Type VIII Larvae (Crustacea : Facetotecta) from the North Pacific. PUBLICATIONS OF THE SETO MARINE BIOLOGICAL LABORATORY 1987, 32(1-3): 141-150

ISSUE DATE:

1987-08-10

URL:

http://hdl.handle.net/2433/176131

RIGHT: 


\title{
Three Forms of Nauplius Y Type VIII Larvae (Crustacea: Facetotecta) from the North Pacific
}

\author{
By \\ Tatsunori Itô \\ Seto Marine Biological Laboratory, Kyoto University, Shirahama, \\ Wakayama 649-22, Japan \\ With Text-figures $1-3$ and Table 1
}

\begin{abstract}
Three forms of nauplius y type VIII larvae (VIII-a, VIII-b, VIII-c) are described from Tanabe Bay on the Pacific coast of Japan. The type VIII larvae are characterized by a peculiar shape of the body, which is extremely flattened dorso-ventrally and with paired notches on anterior side. Three forms are discernible from each other in the armature of appendages as well as in the sculpture on the cephalic shield.
\end{abstract}

In the present paper three forms of closely related nauplius y larvae (Crustacea: Facetotecta) are described from the North Pacific under the symbols VIII-a, VIII$b$ and VIII-c. The type VIII-a was provisionally designated in a former paper (Itô, in press) with a diagram which showed the principal pattern of its cephalicshield sculpture, though description of its detailed morphology has been postponed.

The specimens were selected by me from a sample of a number of facetotectan larvae of different types which were found in a plankton sample collected by Mr. S. Ohtsuka and were sorted out by him. The sample was collected in Tanabe Bay on the Pacific coast of Japan by a horizontal tow of a small plankton net (4 July 1982). The specimens, which had originally been preserved in formalin solution, were mounted onto slide glasses with absolute glycerin and were examined with the phase-contrast or differential interference microscope. The terminology used in this paper follows Itô (in press).

Before going further I would like to express my sincere thanks to Mr. S. Ohtsuka of Hiroshima University, who placed the material at my disposal. This study is supported in part by the Grant-inAid for Scientific Research, No. 62540567, from the Ministry of Education, Science and Culture, Japan.

\section{Nauplius y, type VIII-a}

(Fig. 1)

Material examined: Two specimens of the same size were examined. All of the illustrations given in Fig. 1 were based upon one specimen.

Body (Fig. 1-A, B, C) markedly depressed dorso-ventrally, $400 \mu \mathrm{m}$ long (including caudal horn), $270 \mu \mathrm{m}$ wide, $130 \mu \mathrm{m}$ thick, colorless and semitransparent. Contour of body, when viewed dorsally, sharply constricted at the border between cephalic shield and hind body. Nauplius eye seems to be decolorized during preserva-

Publ. Seto Mar. Biol. Lab., 32 (1/3), 141-150, 1987.

(Article 5) 


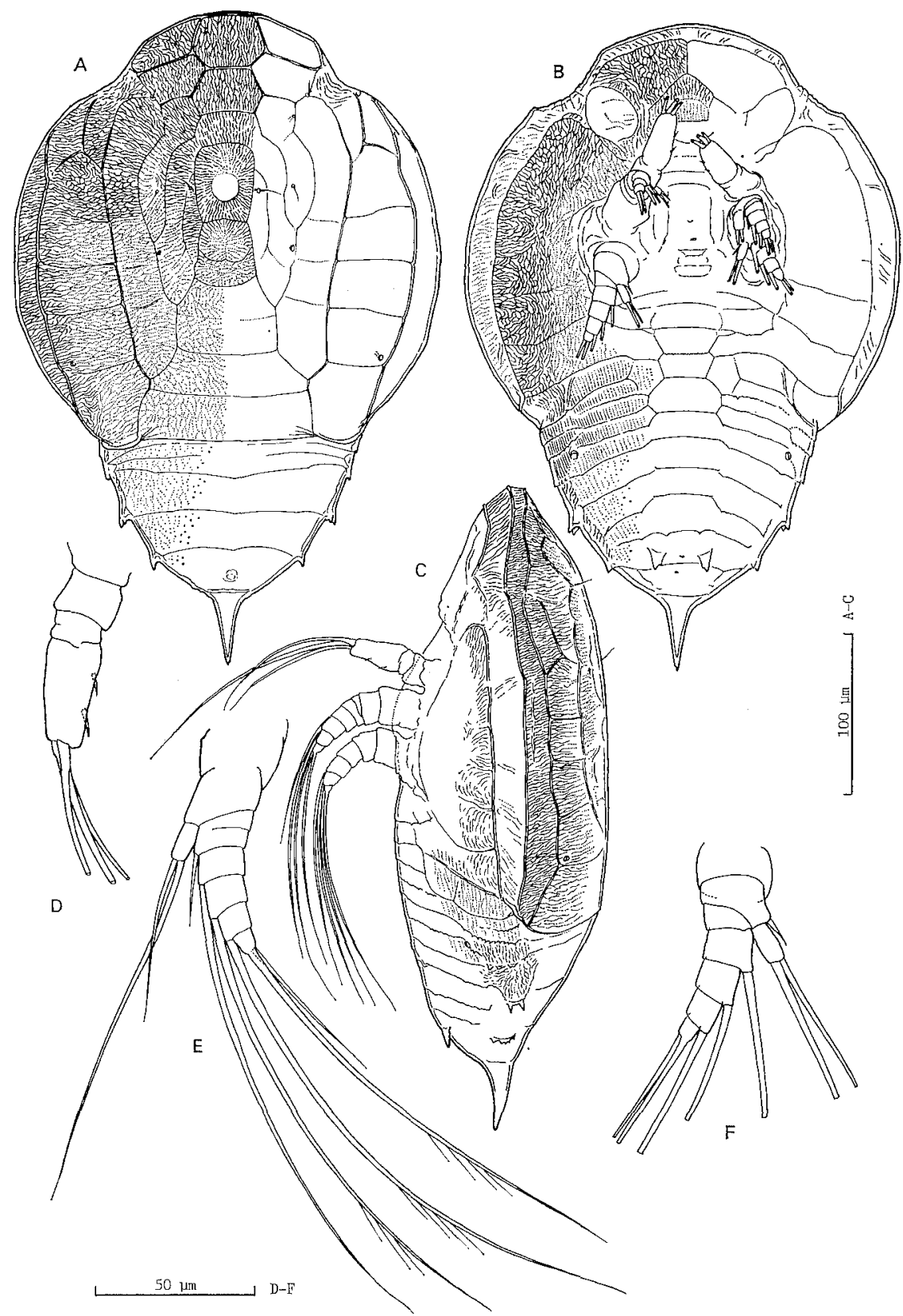

Fig. 1. Nauplius y type VIII-a larva. A. Habitus, dorsal; B. Habitus, ventral; C. Habitus, lateral; D. First antenna; E. Second antenna; F. Mandible.

tion. Cephalon anteriorly with a pair of notches, each placed across $\mathrm{M}-2$ plate and brim. Labrum very low, rather rudimentary (see Fig. 1-B, C), with one medial and two lateral pores. Anterior half of faciotruncal integument decorated with complex mesh-like structure except for a pair of oval areas, which are placed anterior 
to first antennae and almost smooth (Fig. 1-B). Ventral surface of faciotruncal integument posterior to labrum decorated with almost transverse ridges, of which some anterior ones are connected with each other and form a mid-longitudinal row of polygonal plates (at least three complete plates, the middle one accompanied with a hexagonal plate bilaterally); a prominent pore occurring on each ventrolateral surface posterior to cephalic shield; a pair of short spinous projections placed near posterior end. Caudal horn almost straight, $45 \mu \mathrm{m}$ long, pointing backward. Dorsal surface of posterior faciotruncal integument (hind body) furnished with three prominent transverse ridges, each of which terminates in a group of spinous projections bilaterally; mesh-like texture not clear. Dorsocaudal organ represented by a small swirling structure anterior to the caudal horn.

Cephalic shield (Fig. 1-A) $260 \mu \mathrm{m}$ long, with mesh-like texture except for window. Window smooth and round, placed within a large plate (=circum-window) which is formed by fusion of $F-1$ and $0-1$. Apart from the circum-window and window, three frontals and six occipitals are recognized as axial plates. F-2 connected bilaterally with an "arm" which consists of fused E-1 and E-2 (described later). F-3 and F-4 hexagonal, the former smaller than the latter. $0-2$ faintly bipartite. 0-4 trapezoid, 0-5 rectangular; border between $0-4$ and $0-5$ faint. $0-6$ trapezoid. $0-$ 7 rectangular, $110 \mu \mathrm{m}$ wide. $\mathrm{C}-1$ represented by an almost fusiform plate placed alongside circum-window and $0-2$, with a hair near its anterior tip. $\mathrm{C}-2$ placed alongside $0-3$ and $0-4$. Border between $\mathrm{C}-1$ and $\mathrm{C}-2$ indistinct. $\mathrm{E}-1$ and $\mathrm{E}-2$ forming a common plate which fuses with $\mathrm{F}-2$ anteriorly, with a pore near posterolateral edge. Intercalary plate represented by a long plate which borders on the posterolateral edge of $\mathrm{F}-3$ and extends posteriorly alongside the fused $\mathrm{E}-1$ and $\mathrm{E}-2$. Two parts are discernible in this intercalary plate; its anterior part, which is almost hexagonal and bears a pore near its outer edge, representing I-1; the posterior part, which is long and with a hair almost medially, representing fused $I-2$ and $I-3$. P-1 represented by a hexagonal plate bordering on both $\mathrm{F}-3$ and $\mathrm{F}-4$, with a hair on its outer angle. A very long plate follows $\mathrm{P}-1$, it is a fusion of polygonal plates 2 to 6, inclusive; $\mathrm{P}-4, \mathrm{P}-5$ and $\mathrm{P}-6$ faintly recognizable. Marginal plate-group consisting of seven large plates; $\mathrm{M}-2$ transformed due to notch; $\mathrm{M}-6$ bearing a pore posteriorly. Superlateral plate triangular, deeply wedging itself between $\mathbf{M}-2$ and M-3. Brim clearly seen even in dorsal view except for an anterior portion between notches, forming no plate (cf. Fig. 1-A and B).

First antenna (Fig. 1-D) consisting of two segments; first segment as long as its diameter, bare; second segment about three times as long as first segment, with wrinkles proximally, armed with two widely spaced setulae on its inner face, three setae apically. Second antenna (Fig. 1-E). Coxa with a very small projection on its inner edge. Basis not ornamented. Endopodite represented by a cylindrical segment with two apical setae. Exopodite consisting of five segments, the first partially subdivided by a suture into two incomplete annuli, armed with a setule on its inner distal edge; second, third, and fourth segments each armed with an inner seta; fifth segment armed with two apical setae. Mandible (Fig. 1-F). Coxa not orna- 
mented. Basis armed with a short seta on its inner distal edge. Endopodite represented by a cylindrical segment with two apical setae. Exopodite consisting of five segments, the first bare and not subdivided; armature of apical four segments as in the counterpart in the second antenna.

Remarks. The specimen which was not illustrated accords with the illustrated specimen in the armature of the appendages as well as in the principal structure of the cephalic shield and faciotruncal integument. Characteristics that are useful for identification of type VIII-a larvae are discussed later.

\section{Nauplius y, type VIII-b}

(Fig. 2)

Material examined: One specimen.

Body (Fig. 2-A, B) markedly depressed dorso-ventrally, $405 \mu \mathrm{m}$ long (including caudal horn), $275 \mu \mathrm{m}$ wide, about $130 \mu \mathrm{m}$ thick, colorless and semitransparent. Contour of body, when viewed dorsally, not constricted at the border between cephalic shield and hind body, but gradually tapering from cephalic shield to hind body. Nauplius eye seems to be decolorized during preservation. Cephalon anteriorly with a pair of notches, each placed across M-2 plate and brim. Labrum very low, rather rudimentary (Fig. 2-B), with one medial and two lateral pores. Anterior half of faciotruncal integument decorated with complex mesh-like structure except for a pair of oval areas, which are placed anterior to first antennae and almost smooth (Fig. 2-B). Ventral surface of faciotruncal integument posterior to labrum decorated with almost transverse ridges, of which some anterior ones are connected with each other and form a mid-longitudinal row of polygonal plates (at least two); a prominent pore occurring on each ventrolateral surface posterior to cephalic shield; a pair of short spinous projections placed near posterior end. Caudal horn almost straight, $45 \mu \mathrm{m}$ long, pointing backward. Dorsal surface of posterior faciotruncal integument (hind body) furnished with three prominent transverse ridges, each of which terminates in a group of spinous projections bilaterally; mesh-like texture not clear. Dorsocaudal organ wanting.

Cephalic shield (Fig. 2-A) $268 \mu \mathrm{m}$ long, with mesh-like texture except for window. Window is recognizable as a smooth and round area within fourth axial plate ( $=$ circum-window, which is regarded as a fusion of F-1 and 0-1) because it is not encircled by a clear ridge. Apart from the circum-window and window, three frontals and six occipitals are recognized as axial plates. F-2 connected bilaterally with an "arm" which consists of a fused elongate plate (described later). F-3 and F-4 hexagonal, the former smaller than the latter. 0-2 very faintly bipartite. 0-4 trapezoid. 0-5 almost rectangular, its right edge opening anteriorly into a fused part of crescentic and elongate plates. 0-6 almost trapezoid. 0-7 rectangular, about $120 \mu \mathrm{m}$ wide. Crescentic plate single, with a hair near its anterior extremity. $\mathrm{E}-1$ and $\mathrm{E}-2$ forming a common plate, fused with crescentic plate posteriorly and, 


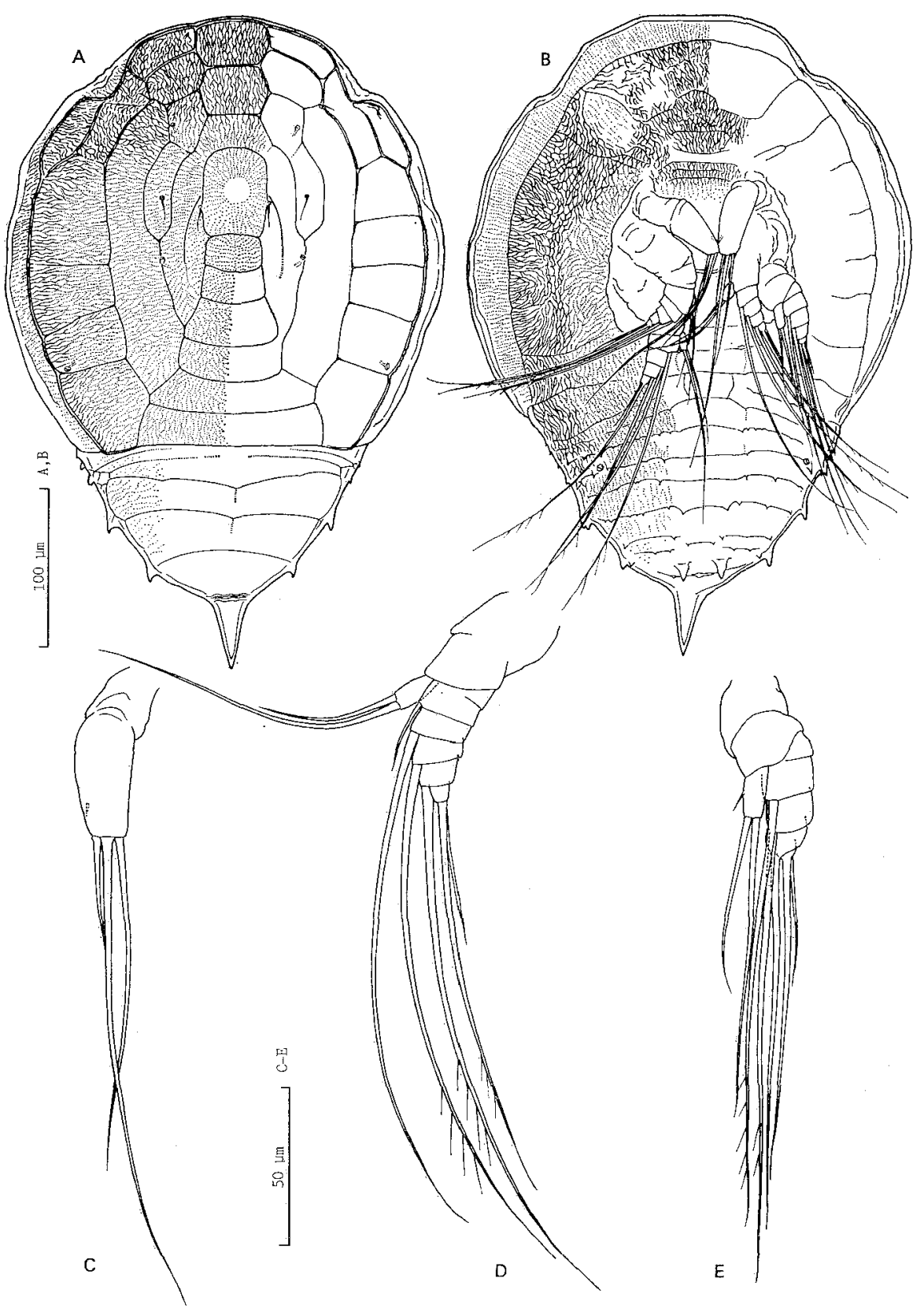

Fig. 2. Nauplius y type VIII-b larva. A. Habitus, dorsal; B. Habitus, ventral; C. First antenna; D. Second antenna; E. Left mandible.

further, fused with F-2 anteriorly, bearing a pore on outer rim a little posterior to intercalary plate. Intercalary plate represented by a long plate which borders on the posterolateral edge of F-3 and extends posteriorly alongside the fused E-1 and E-2. Two parts are discernible in this intercalary plate; its anterior part, which is 
almost hexagonal and bears a pore near its outer edge, representing I-1; the posterior part, which is long and with a hair almost medially, representing fused I-2 and I-3. P-1 represented by a hexagonal plate bordering on both F-3 and F-4, with a hair on its outer angle. A very long plate follows $\mathrm{P}-1$, it is a complete fusion of polygonal plates 2 to 6 , inclusive. Marginal plate-group consisting of seven large plates; M-2 transformed due to notch; M-6 bearing a pore posteriorly; border between left $\mathrm{M}-3$ and $\mathrm{M}-4$ unclear. Superlateral plate triangular, wedging itself between $\mathrm{M}-2$ and $\mathrm{M}-3$. Brim clearly seen even in dorsal view except for anterior portion between notches, forming no plate.

First antenna (Fig. 2-G) consisting of two segments; first segment as long as its diameter, bare; second segment about three times as long as first segment, with wrinkles proximally, with one setule on inner surface subapically, three setae apically. Second antenna (Fig. 2-D). Coxa without a projection on its inner edge (see remarks). Basis not ornamented. Endopodite represented by a cylindrical segment with two apical setae. Exopodite consisting of five segments, the first partially subdivided by a suture into two incomplete annuli, armed with a setule on its inner distal edge; second, third, and fourth segments each armed with an inner seta; fifth segment armed with two apical setae. Mandible (Fig. 2-E). Coxa not ornamented. Basis armed with no seta on its inner edge. Endopodite represented by a cylindrical segment with two apical setae. The endopodite of left mandible bears a setule on its inner side, but such a setule is not present on the endopodite of right mandible (see remarks). Exopodite consisting of five segments, the first bare and not subdivided by a suture; armature of apical four segments as in the counterpart in the second antenna.

Remarks. This larva clearly differs from VIII-a larvae in the appearance of the body because the contour of the former is not constricted at the border between cephalic shield and hind body but gradually tapers from the cephalic shield to the hind body (cf. Figs 1-A and 2-B). This VIII-b larva lacks a dorso-caudal organ, while VIII-a larvae have a dorso-caudal organ represented by a small swirling structure.

Due to the limitation of material, variability in this form is unknown. However, asymmetrical nature in the cephalic shield sculpture as well as in the mandibular structure can be regarded as a part of the possible variability. It is unknown whether the mandibular endopodite with a lateral setule is normal or not. I have described above that the coxa of second antennae has not a projection on its inner edge. However, a small projection like that in the VIII-a larvae might be overlooked from the inner edge of the coxa. Even in the VIII-a larvae, it was often difficult to see the projection depending on the orientation of specimen. Other characteristics which are available to identify this form, type VIII-b, are dealt with later.

\section{Nauplius y, type VIII c}

(Fig. 3)

Material examined: One specimen.

Body (Fig. 3-A, B) markedly depressed dorso-ventrally, $450 \mu \mathrm{m}$ long (including 


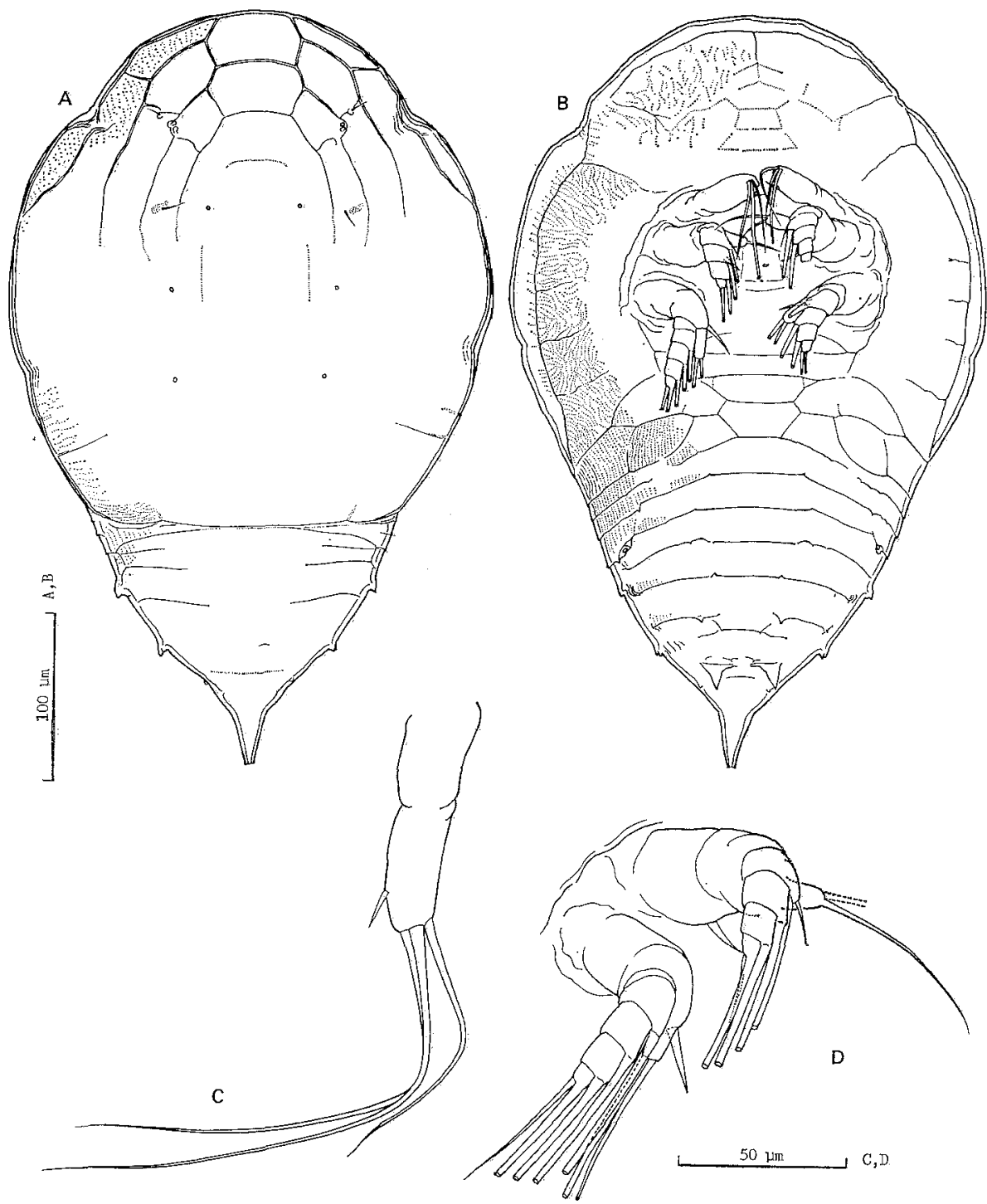

Fig. 3. Nauplius y type VIII-c larva. A. Habitus, dorsal; B. Habitus, ventral; C. First antenna; D. Second antenna (upper) and mandible in situ.

caudal horn), $290 \mu \mathrm{m}$ wide, about $140 \mu \mathrm{m}$ thick, colorless and semitransparent. Contour of the body not constricted at the border between cephalic shield and hind body, but gradually tapering from cephalic shield to hind body. Nauplius eye seems to be decolorized during preservation. Cephalon anteriorly with a pair of notches, each placed across incomplete M-2 plate (mentioned later) and brim. Labrum very low, rather rudimentary (see Fig. 3-B), with one medial and two lateral pores. Mesh-like texture of faciotruncal integument very faint. Ventral surface of faciotruncal integument posterior to labrum decorated with almost trans- 
verse ridges, of which some anterior ones are connected with each other and form a mid-longitudinal row of two polygonal plates accompanied with incomplete plates bilaterally; a prominent pore occurring on each ventrolateral surface posterior to cephalic shield; a pair of short spinous projections placed near posterior end. Caudal horn almost straight, pointing backward, basally widening, not defined at base. Dorsal surface of posterior faciotruncal integument (hind body) furnished with transverse ridges which are medially interrupted (see Fig. 3-A); mesh-like texture very faint. Dorsocaudal organ wanting (a slight depression or scar representing it?).

Cephalic shield (Fig. 3-A) $305 \mu \mathrm{m}$ long, almost smooth; mesh-like texture present only marginally. Following anterior plates are clearly recognized: F-4, F-3, I-1, $\mathrm{P}-1, \mathrm{M}-1$, and $\mathrm{S} . \mathrm{F}-4$ and $\mathrm{F}-3$ hexagonal, subequal in size. I-1 with a pore (two pores?) near its outer angle, accompanied posteriorly by a long incomplete plate which represents I-2. This incomplete I-2 disappearing posteriorly, with a hair. P-1 hexagonal, accompanied posteriorly with a long incomplete plate which bears a hair anteriorly and disappears posteriorly. M-1 clearly delimited from $\mathrm{M}$ 2 by a ridge. M-2 incomplete, widening behind notch, disappearing posteriorly. Three pairs of pores present around the center of cephalic shield, the first pair placed between two hairs, each of which arises from an incomplete intercalary plate. Border between $M-6$ and $M-7$ present behind a lateral pore. Brim scarcely seen in dorsal view.

First antenna (Fig. 2-C) consisting of two segments; first segment about 1.5 times as long as its diameter, bare; second segment somewhat longer than first segment, with a weak wrinkle proximally, armed with a short seta on its inner face subapically, three setac apically. Second antenna (Fig. 2-D). Coxa armed with a stout seta on its inner edge. Basis with no seta. Endopodite represented by a cylindrical segment with two apical setae (see remarks). Exopodite consisting of five segments, the first partially subdivided by a suture into two incomplete annuli, armed with a setula on its inner distal edge; second, third, and fourth segments each armed with an inner seta; fifth segment armed with two apical setae (see remarks). Mandible (Fig. 2-D). Coxa not ornamented. Basis armed with a stout seta on its inner distal edge. Endopodite represented by a cylindrical segment with two apical setae. Exopodite consisting of five segments, the first bare and not subdivided; armature of apical four segments as in the counterpart in the second antenna.

Remarks. An endopodite seta of the right second antenna and three setae (two apical and one subapical) on the exopodite of the left second antenna were broken during rotation of the specimen on a slide glass.

This VIII-c larva is similar to VIII-b larva rather than to VIII-a larvae in the general appearance of body. This larva is larger than the VIII-a and VIII-b larvae.

The first pair of pores around the center of the cephalic shield corresponds with the pair of hairs arising from $\mathrm{C}-1$ in the VIII-a larvae. The next pair of pores 
corresponds with the pair of pores on the fused E-2 in the VIII-a larvae. However, the last pair of pores does not correspond with any possible counterpart in the VIIIa larvae. Other characteristics which are available to identify this form, type VIIIc, are dealt with later.

\section{Discussion}

Three forms of nauplius y type VIII larvae are all characterized by the dorsoventrally depressed body with paired notches anteriorly. This depressed appearance is derived mainly from lateral extension in their cephalon. Their cephalic shield laterally extends and forms an almost flat surface, then their marginal plates, which are arranged on a curved surface and not always fully seen in other types of first naupliar stage (see Itô, 1986, Fig. 2), are clearly seen from dorsal side. In VIII-a and VIII-b larvae, even brim is clearly seen from dorsal side, though this part can be fully seen only from lateral side in other types (see Hansen, 1899, Schram, 1972, Itô, 1986).

Type VIII larvae are greatly different from other nauplius y larvae in the sculpture of their cephalic shield because certain plates of their cephalic shield show a strong tendency to fuse themselves. For example, in the VIII-b larva the long plate which follows $\mathrm{P}-1$ is a fusion of posterior five polygonals, which are recognized as separate plates in type IV (Hansen, 1899, Schram, 1972) and other similar nauplius y larvae such as types IX, X and XI (Itô, in press). In contrast, some posterior polygonals are barely recognizable in the VIII-a larvae (Fig. 1-A). This appearance can be understood as an intermediate condition between a derived condition seen in the VIII-b larvae and the possible original one seen in types IV, IX, X and XI (Itô, in press). Furthermore, there is no doubt that the circum-window plate in the VIII-a and VIII-b larvae is a fusion of $F-1$ and $0-1$, which are recognized as separate plates in type IV and other similar nauplius y larvae (Itô, in press). As seen in the VIII-a and VIII-b larvae, crescentic, elongate, and intercalary plates also show a similar tendency to fuse.

In contrast to the VIII-a and VIII-b larvae, the VIII-c larva (Fig. 3-A) is aberrant in the structure of its cephalic shield, although its anterior plates are almost as in the formers. Smoothness of its texture and its undeveloped ridges, which should form posterior plates if they developed, might represent an individual abnormality because similar phenomena have been known to appear as an abnormality in certain nauplii of separate types (unpublished). However, even if the cephalic shield of this larva was abnormal, the form VIII-c is still clearly discernible from the forms VIII-a and VIII-b because armatures of appendages are different.

The differences in their appendages are summarized in Table 1. It shows that armatures of all three pairs of appendages are available to distinguish them. The apical segment of first antennae has two inner setae in the VIII-a larvae, but the counterparts in the VIII-b and VIII-c larvae have only one seta. The VIII-c larva bears an enditic seta on each coxa of second antennae as well as on each basis 
Table 1. Differences in appendages of three forms of type VIII larvae. ( + : present; - : absent)

\begin{tabular}{lccc}
\hline \hline & VIII-a & VIII-b & VIII-c \\
\hline $\begin{array}{c}\text { The number of inner setae of the } \\
\text { apical segment of first antenna }\end{array}$ & 2 & 1 & 1 \\
$\begin{array}{c}\text { Enditic seta of the coxa of second } \\
\text { antenna }\end{array}$ & $\begin{array}{c}\text { (rudimentary } \\
\text { protuberance) }\end{array}$ & - & + \\
$\begin{array}{l}\text { Enditic seta of the basis of mandi- } \\
\text { ble }\end{array}$ & + & - & + \\
\hline
\end{tabular}

of mandibles. These enditic setae of the VIII-c larva are very stout and prominent. A similar enditic seta is present on each basis of mandibles of the VIII-a larvae, but the VIII-b larva does not have such enditic seta either on the second antennae or on the mandibles. It is unlikely that all of these differences among three forms represent mere individual variation. I believe that these three forms are all separate species.

Up to the present, one nauplius which is undoubtedly assignable to type VIII has already been raised into cypris y stage in the laboratory (unpublished). However, its cephalic shield can not be simply compared with the counterpart in the three forms described in this paper because its initial stage observed in the laboratory was not first naupliar stage but second naupliar stage. This reared nauplius larva, which is described elsewhere, is similar to the VIII-a larvae in the armature of second antennae and mandibles, but even if possible developmental changes are taken into consideration a characteristic of its first antennae is unreasonable for a VIII-a larva. It might be another separate species. Whether or not it is a separate species, there is little doubt that a group of closely related species which produce type VIII larvae is present within the Facetotecta.

\section{References}

Hansen, H.J. 1899. Die Gladoceren und Cirripedien der Plankton-Expedition. Ergebn. PlanktonExp. Humboldt-Stifung, 2(G.d): 1-58, pls I-IV.

Itô, T. 1986. Three types of "nauplius y" (Maxillopoda: Facetotecta) from the North Pacific. Publ. Seto Mar. Biol. Lab., 31: 63-73.

- (in press) Proposal of new terminology for the morphology of nauplius y (Crustacea: Maxillopoda: Facetotecta), with provisional designation of four naupliar types from Japan. Zool. Sci., 4.

Schram, T.A. 1972. Further records of nauplius y type IV Hansen from Scandinavian waters. Sarsia, 50: 1-24. 